\title{
Comunión y trabajo: el ser humano al servicio de la creación*
}

\author{
Juan David Patiño Salazar ${ }^{a}$ \\ Pontificia Universidad Javeriana, Colombia \\ http://orcid.org/0000-0001-9246-0546 \\ Uriel Salomón Salas, S. J. \\ Pontificia Universidad Javeriana, Colombia \\ http://orcid.org/0000-0002-1827-9172
}

RECIBIDO: 08-08-19. APROBADO: 07-03-20

Resumen: De cara a la crisis medioambiental en la que nos encontramos sumergidos, en gran medida debido a las acciones de explotación de los recursos naturales por parte de los seres humanos sobre el planeta, vale la pena preguntarnos, ya no solo como individuos y como ciudadanos, sino también como cristianos bautizados, hijos e hijas de una misma Iglesia, cuál es la perspectiva espiritual y teológica a la que se nos invita para mitigar y revertir, en la medida de lo posible, el daño que le hemos hecho a nuestra casa común.

Es en el horizonte de esta pregunta en el cual surge el presente escrito como forma de enriquecer las reflexiones teológicas actuales en torno de la ecología y el cuidado del medio ambiente. Así, el artículo aquí propuesto presenta tres categorías teológicas que se proponen como elementos que pueden iluminar una reflexión en torno de la creación, a saber: la comunión como símbolo de la armonía de la creación; el trabajo de Dios y el trabajo del ser humano; y la centralidad del ser humano en la obra creada. Para desarrollar esta propuesta, se realiza un ejercicio dinámico y dialógico, en tres apartados que obedecen a las tres categorías sugeridas, entre los dos relatos de creación del Génesis y la contemplación para alcanzar amor de los Ejercicios Espirituales de San Ignacio de Loyola, en el que se extraen los aspectos más importantes para alimentar la comprensión de cada una de las categorías propuestas desde el aspecto bíblico y desde el aporte espiritual-cristiano. Al final se concluye que el ser humano es esencial en la creación, no como su dominador ni como su explotador desmedido, sino como el que trabaja por su cuidado desde la perspectiva de la comunión y del amor respetuoso.

Palabras Clave: Comunión; trabajo; cuidado y protección del ser humano hacia la creación; relatos de creación; contemplación para alcanzar amor.

*Artículo de reflexión.

${ }^{a}$ Autor de correspondencia. Correo electrónico: patino.juan@javeriana.edu.co 


\section{Communion and Labor: The Human Being at the Service of Creation}

AвSTRACт: Due to the environmental crisis in which we find ourselves submerged, largely due to human beings' actions of exploitation of natural resources on the planet, it is worth asking ourselves, not only as individuals and as citizens, but also as baptized Christians, sons and daughters of the same Church, what is the spiritual and theological perspective to which we are invited to mitigate and reverse, as far as possible, the damage we have done to our common house. It is on the horizon of this question in which the present writing emerges as a way to enrich current theological reflections on ecology and care for the environment. Thus, this article presents three theological categories that are proposed as elements that can illuminate a reflection on creation, namely: communion as a symbol of the harmony of creation; the work of God and the work of the human being; and the centrality of the human being in the created world. To develop this proposal, a dynamic and dialogic exercise is carried out, in three sections, between the two creation stories of Genesis and contemplation to reach love of the Spiritual Exercises of San Ignacio de Loyola, from which the most important aspects are extracted to feed the understanding of each one of the categories proposed from the biblical aspect and from the spiritual-Christian contribution. In the end, it concludes that the human being is essential in creation, not as its dominator nor as its excessive exploiter, but as the one who works for its care from the perspective of communion and respectful love.

Key Words: Communion; Labor; Human Being's Care and Protection toward Creation; Creation Stories; Contemplation to Reach Love.

\section{Cómo CITAR:}

Patiño Salazar, Juan David, y Uriel Salomón Salas. "Comunión y trabajo: el ser humano al servicio de la creación". Theologica Xaveriana (2021): 1-28. https://doi.org/10.11144/ javeriana.tx71.ctshsc 


\section{Introducción}

El mundo contemporáneo está atravesando una crisis ecológica de magnitudes incalculables; el calentamiento global, los gases de efecto invernadero, las toneladas de basuras acumuladas en los océanos, la extinción masiva de especies de plantas y de animales, son evidencias de que nuestro planeta está en una situación crítica; y el causante, en gran medida, es el ser humano con su actividad industrial incontrolada y con su idea de progreso exacerbada.

Ante este panorama, muchas organizaciones privadas y estados han empezado a tomar medidas para mitigar el daño causado a la Tierra, y muchas personas, de forma individual, han migrado hacia una conciencia ecológica que las ha puesto en el horizonte de una relación respetuosa y armónica con la naturaleza. Este despertar ecológico nos conduce a cuestionarnos, a los que somos personas de fe, bautizados, hijos de Dios, sobre lo que hemos hecho y debemos hacer para mejorar, mejor aún, para resignificar nuestra relación con nuestro entorno natural.

Precisamente, para intentar dar respuesta a tales cuestionamientos y con el ánimo de ofrecer elementos que iluminen nuestra vida de fe desde una reflexión teológica seria y académica, nos hemos remitido al estudio de dos textos que consideramos pertinentes para abordar esta temática, a saber, los dos relatos de creación del Génesis (Gn 1,1-2,3 y Gn 2,4-25), como aporte desde la teología bíblica, y la "Contemplación para alcanzar amor" de los Ejercicios Espirituales de San Ignacio de Loyola', como aporte desde la espiritualidad cristiana.

A partir del análisis de ambos textos encontramos tres categorías que juzgamos sugestivas e interesantes para proponer una reflexión teológica en torno de la creación que nos proporcione elementos orientadores para construir, desde nuestro ser Iglesia, unas relaciones sanas, armónicas y amorosas con la obra creada, conscientes de que en ella habita de manera sublime la presencia del Creador. Tales categorías son:

- La comunión como símbolo de la relación tranquila y respetuosa entre el ser humano y el resto de la creación.

- $\quad$ El trabajo de Dios por el mantenimiento de la vida y el trabajo del ser humano como forma de vincularse a ese proyecto vivificador de Dios.

- El papel central del ser humano en la creación, en tanto representante de Dios en la tierra y, por tanto, responsable de cuidar y proteger la vida de la creación tal y como Dios mismo lo hace.

\footnotetext{
${ }^{1}$ San Ignacio de Loyola, Ejercicios espirituales 230-237.
} 
Estas tres categorías serán desarrolladas a lo largo del presente escrito mediante un ejercicio dinámico y dialógico entre los textos del Génesis y el texto ignaciano. Se trata de exponer con claridad los aspectos esenciales de cada una de ellas en el horizonte de una reflexión teológica que nos comprometa, desde nuestra fe y nuestra vida eclesial, con el cuidado de la madre tierra, resignificando nuestra relación con la naturaleza como lugar donde yace vívidamente la presencia del Creador. Para ello presentaremos las tres categorías en tres apartados:

- La comunión como símbolo de la armonía de la creación

- El trabajo de Dios y el trabajo del ser humano

- El ser humano: protagonista en el cuidado y protección de la creación

Con este trabajo de reflexión teológica hacemos un aporte a los esfuerzos realizados en todo el mundo para superar la compleja y grave crisis ecológica en la que nos encontramos sumergidos, conscientes de que "dentro de cada uno se encuentra la presencia del Espíritu que solo espera la oportunidad que nosotros le demos para humanizarnos, y así poder soñar con una sociedad nueva, gracias a nuestro esfuerzo colectivo"2.

\section{La comunión como símbolo de la armonía de la creación}

Cuando hablamos de comunión podemos hacerlo en varios sentidos, pues el término tiene varias acepciones. Con todo, desde el punto de vista etimológico, tenemos que comunión viene del latín cum que significa con y del latín unio que significa unión, es decir, comunión significa unión con otro ${ }^{3}$. Situados en esta perspectiva podemos considerar entonces que hablar de comunión es hablar de alteridad, de una realidad más allá del individualismo, de una condición que nos pone en salida al encuentro de otro.

En efecto, cuando nos detenemos por un momento a pensar en la condición propia del ser humano, nos damos cuenta de que, desde que nace,

...se manifiesta con una serie de carencias, que ve colmadas mediante el amor y la ayuda solidaria de la familia. De ahí que descubra su alteridad. El ser humano, en otras palabras, experimenta en sí mismo la necesidad de abrirse a las cosas, a las personas y, sobre todo, a Dios. ${ }^{4}$

\footnotetext{
${ }^{2}$ Alonso Schökel, La biblia de nuestro pueblo, 21.

${ }^{3}$ Parente, Piolanti y Garofalo, Diccionario de teología dogmática, 75.

${ }^{4}$ Pikaza y Silanes, Diccionario teológico. El Dios cristiano, 244.
} 
Esta dimensión de comunión que es propia de los seres humanos la encontramos en su máxima expresión en el Dios Trinidad cuyo proyecto de salvación, al crear al hombre a su imagen y semejanza, se funda sobre la realidad de la comunión, no sobre la individualidad de cada uno. Así lo expresa claramente el Concilio Vaticano II, en su decreto Ad gentes: “...plugo a Dios llamar a los hombres a la participación de su vida no solo en particular, excluido cualquier género de conexión mutua, sino constituirlos en pueblo, en el que sus hijos que estaban dispersos se congreguen en unidad"s. Entonces podemos afirmar -con el magisterio de la Iglesia- que, desde el horizonte de la creación, el hombre está llamado a la comunión en cuanto su Creador es él mismo hecho comunión.

Tal realidad de comunión la encontramos reiteradamente en las Sagradas Escrituras y en el acervo espiritual y teológico de la tradición cristiana. En efecto, en los textos que nos ocupan en este escrito, a saber, los relatos de creación del Génesis y la "Contemplación para alcanzar amor" de los Ejercicios espirituales de San Ignacio, hallamos elementos que nos permiten hablar de esta dimensión de comunión. En lo que respecta a los relatos de creación del Génesis, es menester que nos detengamos por un momento en algunos detalles que el autor sagrado nos brinda, para iluminar lo que ya hemos dicho hasta el momento respecto de la realidad de comunión.

Pues bien, de acuerdo con el primer relato de creación (Gn 1,1-2,3), en el día sexto aparece en escena el hombre, que viene a completar la obra iniciada con la aparición de los animales terrestres (Gn 1,24-31). Desde la perspectiva semita del relato, el ser humano se halla en la cúspide de la creación y lo evidencia el que Dios mismo participa de modo más íntimo e intenso en su acto creador, por lo menos desde lo que nos comunica tal relato. De igual forma nos encontramos aquí el verbo bará (crear, en hebreo) que aparece tres veces en el v. 27, para darnos a entender que -con esta última obra- el significado del verbo ha alcanzado todo su sentido ${ }^{6}$.

Ahora bien, luego de que el autor sagrado nos presenta la creación del ser humano y su bendición por parte del Creador, nos propone -en los vv. 29 y $30 \mathrm{del}$ capítulo primero- el alimento que Dios le concede a los animales y al ser humano, a saber, las plantas seminíferas y los árboles para el ser humano, y la hierba verde para los animales. Si bien hallamos aquí un tipo de gradación del mundo vegetal'7, es sugestivo encontrar que, para la mentalidad semita plasmada en este relato, tanto

\footnotetext{
${ }^{5}$ Concilio Vaticano II, “Decreto Ad gentes. Sobre la actividad misionera de la Iglesia (1965)” 2.

${ }^{6}$ Von Rad, El libro del Génesis, 66ss.

${ }^{7}$ A este respecto, José Loza nos dirá: "Lo que la tierra produce guarda un orden: hay clases o especies, como habrá especies en los animales marinos, las aves y los animales terrestres" (Loza, Comentarios a la Nueva Biblia de Jerusalén. Génesis 1-11, 58).
} 
los seres humanos como los animales tienen el mismo alimento, y podríamos decir -de forma más simbólica-, que comparten la misma mesa.

Cuando pensamos en alimento nos viene la idea de compartir, de poner en común, de poner a disposición de los comensales la comida que hay en la mesa, ya que comer es gesto que convoca, que para muchas culturas es motivo de encuentro y de solidaridad, tal como lo expresa Mauricio Waldman en su escrito "Eco-kasher y oiko-menismo": "Comer en comunión es el supremo gesto de la solidaridad".

Entonces, este elemento de gozar del mismo alimento otorgado por el Creador nos parece más sugerente para hablar de una comunión paradisíaca entre los animales y el ser humano en esta altura del primer relato de creación, ya que el hecho de que tanto los seres humanos como los animales tengan a su disposición la misma fuente de alimento (la cual, dicho sea de paso, brota de la tierra a la que Dios mismo le ha dado poder para que de ella surja vida ${ }^{9}$ ) nos permite establecer la relación de comunión entre los animales y el ser humano; comunión en cuanto el hecho de compartir la misma fuente de alimento para garantizar el mantenimiento de la vida pone a los animales y al ser humano en plano de solidaridad, de convivencia pacífica, por decirlo de alguna forma, de equilibrio y armonía paradisíacos.

Más aún, podríamos decir que, hasta este momento del relato, no hay matanzas, es decir, no hay lugar para sacrificios de animales por parte del ser humano ni tampoco hay matanzas de los animales creados entre sí.

Es el único rasgo paradisíaco de todo el capítulo. La creación es todavía tal como Dios la quiso. Dios ama la vida, no quiere la muerte. De él no ha salido la orden de matar para comer. El hombre y los animales todos se alimentan de vegetales. El hombre, amigo de Dios, lo es también de todos los animales; y los animales son amigos del hombre y entre sí. ${ }^{10}$

Esta especie de paz y armonía paradisíacas vienen a reafirmar la perspectiva de comunión que ya hemos venido desarrollando y que se constituye en la primera

\footnotetext{
8 Waldman, "Eco-kasher y oiko-menismo", 13.

9 Aquí vale la pena mencionar cómo, desde el horizonte de este primer relato de creación, la tierra es dadora de vida, pues Dios le ha comunicado ese poder. Por ello, al hablar de la creación del día tercero, en el que aparece la tierra, Westermann afirma: “...el sujeto interpelado es la tierra, la cual en este acto creador es llamada a participar sustantivamente en él y recibe los correspondientes poderes para ello" (Westermann, Genesis, 9). Y, en el mismo sentido, Botta, en su aproximación al estudio del Pentateuco, a propósito de la creación de la tierra, dice: "La tierra está hecha para recibir vida. Para eso fue creada, este es su destino" (Botta, El Pentateuco. La Biblia hebrea en perspectiva latinoamericana. Introducción al Antiguo Testamento, 59).

${ }^{10}$ Ibáńez, Para comprender el libro del Génesis, 25.
} 
categoría a la cual hemos querido aludir en este itinerario reflexivo en torno del cuidado y el respeto por la creación al que nos invita el texto sagrado.

Ahora bien, no solo encontramos dicha realidad de comunión entre el ser humano y los animales en el primer relato de la creación: también en el segundo relato (Gn 2,4-25) -más específicamente en los vv. 18-19- se hace evidente tal dimensión. En efecto, después de que Dios ha llamado a la vida al ser humano y lo ha puesto en el jardín del Edén, considera que no es bueno que permanezca solo y entonces llama a la vida a los animales y se los da para que le hagan compañía y para que les ponga nombres.

Aquí vale la pena resaltar dos aspectos que ayudan a ampliar nuestra comprensión respecto de la comunión. Por una parte, esta idea, atribuida por el narrador a Dios Yahveh de buscarle compañía al ser humano nos permite descubrir un sentido profundo de lo que constituye la humanidad, a saber, el carácter comunitario.

El hombre está hecho para la comunión, la comunidad. [...]. El hombre no es autosuficiente, sino que es "el otro" y "la otra" quien "humaniza" al hombre, quien le da la posibilidad de hacer operativa su capacidad de amar de comunicarse, de vivir plenamente. ${ }^{11}$

Por eso, Dios decide formar todos los animales y, posteriormente, a la mujer.

Por otra parte, el hecho de que el ser humano otorgue nombre a los animales implica que extiende hacia estos la bendición antes recibida $(\mathrm{Gn} 1,28 \mathrm{~b})^{12}$, o sea, la identificación es para alcanzarles la bendición ${ }^{13}$. Adán los asume como su pertenencia, lo que nos indica que él guarda profunda relación con estas criaturas, de manera que establece una dinámica de comunión con ellas.

De acuerdo con el escenario en el que nos ubica el relato podemos decir entonces que tanto los animales como el ser humano gozan de una relación pacífica o de una bendición extendida, tal como lo señalamos a partir del primer relato, lo que nos permite enriquecer la dimensión de comunión con la obra creada que hemos estado proponiendo.

En el mismo sentido podemos afirmar que, desde lo que nos presenta el autor sagrado en los relatos de creación existe parentesco entre todas las formas de vida creadas, en este caso, entre los animales y el ser humano, que hacen de la creación un

${ }^{11}$ Botta, El Pentateuco. La Biblia hebrea en perspectiva latinoamericana. Introducción al Antiguo Testamento, 65.

${ }^{12}$ Botterweck, Ringgren y Fabry, Theological Dictionary of the Old Testament II, 9.

${ }^{13}$ Ibíd., 16. 
reflejo constante de la comunión que anida en su Creador. Tal parentesco, dicho sea de paso, está bien evidenciado incluso por la ciencia moderna:

El parentesco básico de todas las formas de vida en la Tierra está bien establecido científicamente: los mismos aminoácidos, la misma simetría de moléculas orgánicas, el mismo modo de transmitir la información genética, son claras razones para afirmarlo. ${ }^{14}$

Hasta aquí nos hemos centrado en la revisión sucinta de los dos relatos de creación del Génesis y de lo que en ellos encontramos respecto de la categoría de comunión entre el ser humano y el resto de la creación; pero también hemos dicho que en la tradición espiritual cristiana podemos encontrar numerosos ejemplos de la vivencia de tal comunión por medio de la oración, la contemplación y la praxis cotidiana de la vida de fe. Así, hombres de Iglesia como San Francisco de Asís ${ }^{15}$ o como San Juan de la Cruz $^{16}$, a través de su vida y escritos hicieron palpable esa realidad de comunión entre el ser humano y el resto de la creación, en la cual ellos encontraron un lugar privilegiado para hallar la presencia de Dios.

No lejos de ellos, en sus propuestas y manera de vivir la relación con la creación, San Ignacio de Loyola, en su libro Ejercicios espirituales, propone un itinerario de oración que finaliza con el ejercicio que llamó "Contemplación para alcanzar amor". En él invita a contemplar a Dios presente en todos los seres creados. Lo abordaremos en lo que sigue de este apartado, por considerarlo sugerente para enriquecer la reflexión que aquí nos ocupa.

"Contemplación para alcanzar amor"17 es una especie de manual de oración que -como el resto del contenido de los Ejercicios- fue escrito por el santo para ser orado más que para ser leído. Se compone de dos notas aclaratorias, dos preámbulos y cuatro puntos en los que Ignacio invita a quien finaliza los Ejercicios a contemplar a Dios presente en todo lo creado, y con ello, entrar en comunión con el Creador en y desde esa obra creada. De hecho, los estudiosos de la obra Ejercicios espirituales lo enmarcan en el clásico recorrido de las tres vías que todo cristiano debe ir realizando a lo largo de su camino de fe, a saber, la purgativa, la iluminativa y la unitiva.

\footnotetext{
${ }^{14}$ Carreira, "El Génesis en términos de la ciencia moderna”, 13.

${ }^{15}$ Véase a Crescimbeni, San Francisco de Asís, obra que recopila datos biográficos y el famoso "Cántico de las criaturas", entre otros escritos del santo, los cuales evidencian su convicción sobre la comunión que debe reinar entre el hombre y demás seres creados.

${ }^{16}$ El texto titulado, Poesía completa, cuya edición e introducción realiza Cristóbal Cuevas García, presenta la poesía de San Juan de la Cruz, en la cual encontramos su "Cántico espiritual", que es toda una alabanza a Dios presente en la obra creada.

${ }^{17}$ San Ignacio de Loyola, Ejercicios espirituales 230-237.
} 
La primera evoca la primera semana de los Ejercicios, en la cual el ejercitante reconoce su realidad pecadora y se abraza en la misericordia de Dios. La segunda es un momento especial de acogida de la luz de la Palabra y de un saber particular que permite a la persona de fe elegir la voluntad de Dios, mediante un proceso de profunda identificación con Jesús, que Ignacio propone en la segunda semana de sus Ejercicios. La última vía, la unitiva, es el culmen de la vida cristiana, en la cual nos hacemos partícipes de la comunión con Dios y asumimos su vida como parte fundamental de la nuestra, proceso que vive el ejercitante a lo largo de la tercera y cuarta semana de los Ejercicios Espirituales ${ }^{18}$.

En esta última vía se ubica la "Contemplación para alcanzar amor", lo que nos indica de entrada que este ejercicio ya está circunscrito en una dinámica de comunión con Dios y con toda la obra creada, pues pone al ejercitante en la perspectiva de "sentirse creado y criatura en las manos de Dios, y en comunión con toda la realidad creada de manera discreta en la que Dios sigue trabajando en todo momento" ${ }^{19}$.

Sin embargo, no solo es la globalidad de este apartado ${ }^{20}$ de los Ejercicios y su ubicación en la vía unitiva la que nos permite hablar de comunión en la creación; el texto mismo, desde sus inicios, es una invitación constante a entrar en esa lógica de comunión. En efecto, la segunda nota de la "Contemplación", en la que Ignacio afirma que "el amor consiste en comunicación de las dos partes, es a saber, en dar y comunicar el amante al amado lo que tiene o de lo que tiene o puede, y así, por el contrario, el amado al amante" ${ }^{21}$, es también una evidencia clara de la dinámica de comunión a la que se invita al ejercitante; comunión en cuanto comunicación de amor, es decir, en cuanto mutuo intercambio de seres, de sentires, de realidades; más aún, comunión entendida en la perspectiva del amor como "un mutuo "dar y comunicar".

Se trata de un acto de "autotrascendencia" por el que el sujeto sale de sí y entrega su yo con todo lo que es, tiene y puede, a la persona amada, y de un acto de "receptividad" de un tú que a su vez se nos entrega con todas sus cosas" ${ }^{22}$, lo cual supone

\footnotetext{
${ }^{18}$ Rodríguez Osorio, “Contemplación para alcanzar amor”, 11.

${ }^{19}$ Ibíd.

${ }^{20}$ Los Ejercicios Espirituales disponen al ejercitante, de principio a fin, para que entre en una dinámica de comunión con Dios y con la totalidad de la obra creada. La puerta de salida de los Ejercicios viene a ser la "Contemplación para alcanzar amor" y la puerta de entrada el "Principio y fundamento": "Comunión con toda la creación, ya que "las otras cosas sobre la haz [sic] de la tierra son criadas para el hombre, y para que le ayuden'. De modo que el hombre no se sirve de ellas como de un instrumento, sino que establece con ellas un vínculo de armónica correspondencia" (Rambla, "La creación en los Ejercicios -Comunión y servicio-", 232).

${ }^{21}$ San Ignacio de Loyola, Ejercicios espirituales 231.

${ }^{22}$ García de Castro, Diccionario de espiritualidad ignaciana, 151.
} 
salida de sí y encuentro con la alteridad, con lo otro, con lo que es diferente de cada quien; y es esta dinámica la que también vimos explicitada en los relatos de creación.

El dinamismo de comunión al que nos invita Ignacio también lo encontramos en el segundo y el tercer punto del texto que nos ocupa. Ubicado en los numerales 235 y 236 del texto ignaciano, el ejercitante es invitado a contemplar cómo Dios habita en las criaturas, "en los elementos dando ser, en las plantas vegetando, en los animales sensando, en los hombres dando entender; y así en mí dándome ser, animando, sensando y haciéndome entender" ${ }^{23}$.

Más allá de las discusiones respecto del orden en el que se presentan los seres creados y de las potencias que Ignacio atribuye a cada uno (lo cual obedece a una comprensión de la naturaleza muy propia de su época), lo interesante aquí es la invitación a contemplar la presencia de Dios en toda la creación y, nuevamente, a entrar en comunión con él a partir de la comunión con la obra creada.

Es muy sugestivo en este punto -lo cual también se ve en el tercero ${ }^{24}-$ que los verbos utilizados por Ignacio respecto de la habitación de Dios en la creación sean verbos en presente continuo (dando ser, vegetando, sensando, dando entender). Ello significa que, de acuerdo con la visión ignaciana plasmada aquí, el acto creador de Dios es siempre continuo: es decir, Dios sigue habitando las cosas creadas, las sigue creando, les continúa dando ser; más aún, continúa donándose a nosotros en toda su creación ${ }^{25}$, y esto es precisamente lo que Ignacio quiere que el ejercitante reconozca al final de su experiencia de Ejercicios, siempre ubicado en esa dinámica de amor-comunión que él mismo propone en la segunda nota de su texto.

Así las cosas, resulta evidente la presencia de la categoría comunión en el escrito ignaciano, lo cual es de esperar si tenemos en cuenta que en el último ejercicio que propone Ignacio es donde -como ya hemos visto- se invita al ejercitante a entrar en la dinámica de comunión propia del Dios creador; porque si nos detenemos por un momento a pensar en el ser de Dios, nos daremos cuenta de que, desde nuestra fe cristiana y desde lo que nos enseña la tradición teológica, Dios es comunión en cuanto es Dios trino: "Dios es lo que es solo como comunión de personas, cuya particularidad se encuentra en el centro de su ser, pues cada una tiene su propia forma de ser

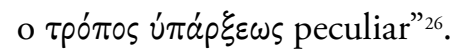

\footnotetext{
${ }^{23}$ San Ignacio de Loyola, Ejercicios espirituales 235.

${ }^{24}$ Ibíd. 236.

${ }^{25}$ Navarrete, "Aproximación bíblico-teológica a la Contemplación para alcanzar amor”, 36-37.

${ }^{26}$ Gunton, Unidad, Trinidad y pluralidad. Dios, la creación y la cultura de la modernidad, 219.
} 
Si ello es así, y si hemos considerado cómo Dios crea los seres hasta el punto de implicarse directamente en el acto creador en el caso de los animales y del ser humano, y si además él habita en todos ellos dando ser, vegetando, sensando, dando entender, no podemos dejar de pensar que esa realidad creada, huella magnífica del Dios creador, es también realidad de comunión; más aún, que tal realidad de comunión debe ser su característica distintiva en cuanto creación. Por ello podemos afirmar con Gunton:

...el mundo creado, como aquello que es peculiarmente lo que es en virtud de su creatureidad refleja de diversas formas el ser de Dios en comunión. La creación humana, hecha a imagen de Dios, refleja más directamente el ser divino en comunión; pero, en virtud de su relación tanto con Dios como con el hombre, el resto de la creación también participa de la relación entre la unidad y la pluralidad que ello conlleva. ${ }^{27}$

En este sentido, tal vez también vale la pena entender el llamado de Ignacio a buscar y hallar a Dios presente en todas las cosas creadas y a reconocer en ellas al creador y Seńor que las habita. Y este reconocimiento nos sumerge inmediatamente en esa dinámica de comunión que acabamos de mencionar. Por tal razón, y con profundo sentido de lo que implica la presencia de Dios en todos los seres de la creación, desde una perspectiva no solo creadora sino también de encarnación, podemos considerar el mundo creado como lugar privilegiado en el que Dios se nos comunica y, con ello, como lugar sagrado de la manifestación de Dios a nosotros ${ }^{28}$.

A propósito de esta última aseveración, Carlos Valverde, al comentar la "Contemplación para alcanzar amor" y su relación con algunos escritos de Teilhard de Chardin, S. J., dice lo siguiente:

En virtud de la creación, y, más aún, de la encarnación, nada es profano aquí abajo para el que sabe ver, y cuando abandonéis el templo y os lancéis a la ciudad trepidante, tendréis el sentimiento de continuar sumergidos en Dios, que os sonríe y os atrae a través de vuestras obras. ${ }^{29}$

\footnotetext{
${ }^{27}$ Ibíd., 246.

${ }^{28}$ Aquí es bueno aclarar que no se trata de proponer un panteísmo en el que todas las cosas y los seres de la naturaleza son divinidades. En este asunto los relatos de creación son muy cuidadosos pues, como vimos, con ellos los autores sagrados quisieron recoger, entre otras cosas, la fe de Israel en un único Dios. También el texto ignaciano es explícito en este tema, pues el hecho de que la "Contemplación para alcanzar amor" esté ubicada al final de los Ejercicios Espirituales, implica que quien la realiza ya ha vivido una experiencia en la que ha ordenado su relación con los seres creados y, en virtud de ello, puede verlos como transparencias del único criador y Seńor por el que ha optado.
}

${ }^{29}$ Valverde, "Contemplación para alcanzar amor y medio divino", 161. 
Vemos entonces cómo el elemento de comunión, que se constituye en realidad de la creación por cuanto su fuente y origen que es Dios, es él mismo comunión y una primera categoría que encontramos tanto en los relatos de creación del Génesis como en la "Contemplación para alcanzar amor" de los Ejercicios espirituales de San Ignacio de Loyola. Esto nos permite encontrar una pista para enriquecer e iluminar una reflexión teológica en torno de la creación, que nos lleve a resignificar las relaciones perversas que hemos mantenido con la obra creada y a reconciliarnos con la madre Tierra, nuestra casa común.

Con todo, además de dicha categoría de comunión, los textos que estamos estudiando en el presente artículo nos alimentan por lo menos con otras dos categorías que vienen a complementar esta primera y que amplían el horizonte de nuestra reflexión. Dediquemos, pues, lo que queda de nuestro escrito a profundizar en ellas.

\section{Trabajo de Dios y trabajo del ser humano}

Una segunda categoría sobre la que quisiéramos ahondar tiene que ver con el trabajo de Dios y el trabajo de los seres humanos. Decimos aquí trabajo de Dios acudiendo a una figura antropomórfica de la divinidad que el mismo autor sagrado nos presenta en el segundo relato de creación (Gn 2,4-25), específicamente en el v. 8, cuando dice que Yahveh Dios plantó un jardín en Edén.

Plantar es una acción que asociamos inmediatamente con el ser humano, máxime si pensamos que este texto hace reminiscencia de la labor agrícola que durante mucho tiempo desempeñó el pueblo de Israel ${ }^{30}$; sin embargo, en este caso, el relato la pone en relación con Dios sugiriéndonos su implicación total en la creación del ser humano para quien él mismo planta el huerto.

Ahora, Dios planta el huerto en Edén para poner allí al hombre y a la mujer y para que ellos "lo labren y lo cuiden", tal y como lo presenta el v. 15 del Capítulo 2 en el segundo relato de creación. Es decir, el ser humano es puesto en el huerto que Dios mismo planta, no para vivir de forma holgazana, sin hacer nada, sino para participar de esa labor agrícola de Dios, cuidando y preservando el huerto que él le ha otorgado para que pueda tener una existencia adecuada.

\footnotetext{
${ }^{30}$ De acuerdo con la teoría documentaria clásica, este relato parece pertenecer a la fuente J, Yahvista, la cual, es más antigua que la fuente P. Por ello, este segundo relato probablemente sea anterior al primero, que ya hemos detallado ampliamente. En él encontramos, no solo una alusión a Dios con el nombre de Yahveh, sino además la recolección de muchas tradiciones arcaicas de Israel juntadas quizá en tiempos de la Ilustración salomónica, pero que quieren mostrarnos un pueblo agrícola, que cultivaba la tierra y que de ella obtenía lo necesario para sobrevivir. Para ampliar esta perspectiva, ver a Von Rad, El libro del Génesis, 115.
} 
Dios, dice el texto, tomó al primer hombre y lo colocó en una huerta, en el paraíso. [...], puso Dios al hombre aquí para que trabajara. La tarea fundamental, radical del hombre, es trabajar. Para no morirse, deberá el hombre alimentarse y este alimento no le va a venir del cielo. El hombre Adán se debe procurar el alimento de la huerta. ¿Cómo? Trabajando. ${ }^{31}$

Esta tarea radical del ser humano, según lo expresa la cita anterior, no es ni debe ser considerada una labor tediosa o una carga impuesta por Dios que, en muchas ocasiones, podría tornarse difícil de asumir. Por el contrario, desde la perspectiva del segundo relato de creación es una forma maravillosa que Dios le ha concedido al ser humano para poder llevar una vida digna, tal y como lo expresa Levoratti en su comentario bíblico latinoamericano sobre este pasaje:

...lo que se quiere resaltar es que el trabajo humano da como resultado lo necesario para comer y para el bienestar. En el huerto el hombre disfruta de lo que produce y el trabajo no es una carga tediosa ni amarga porque es el medio para crear las condiciones de vida que Dios le ha dado. ${ }^{32}$

De igual manera, dicha tarea fundamental del ser humano -que le garantiza su subsistencia en la Tierra- es también, por así decirlo, desde un horizonte más amplio, una forma de vincularse con la labor misma de Dios. No en vano, en este segundo relato, el autor sagrado nos presenta en primera instancia a Dios plantando el huerto, a Dios como agricultor y, en un segundo momento, al ser humano puesto en el jardín para que lo continúe labrando y cuidando.

Desde tal perspectiva, el ser humano es invitado a participar activamente en la labor que Dios desempeña; hay una vinculación profunda entre la acción agricultora de Dios, en este caso, y la tarea del hombre y la mujer, que no consiste simplemente en preservar el huerto para poder subsistir, sino que, en un horizonte más amplio, consiste en unir sus labores a las de Dios para colaborar con él en su proyecto salvífico: "El trabajo [...] constituye la experiencia humana de cuidar y hacer crecer el proyecto divino" ${ }^{33}$.

Este horizonte más amplio del trabajo es precisamente el que San Ignacio invita a considerar en su "Contemplación para alcanzar amor": “...considerar cómo Dios trabaja y labora por mí en todas cosas criadas sobre la haz de la tierra" ${ }^{34}$, de tal suerte que el ejercitante reconozca en cada uno de los seres creados la presencia del Dios

\footnotetext{
${ }^{31}$ Loza Vera y Duarte Castillo, Introducción al Pentateuco. Génesis, 142.

${ }^{32}$ Levoratti, Comentario biblico latinoamericano, 373.

${ }^{33}$ Darder, El verdadero Israel testigo del Dios liberador. Itinerario de vida cristiana a la luz del Pentateuco y los libros históricos, 67.

${ }^{34}$ San Ignacio de Loyola, Ejercicios espirituales 236.
} 
que los habita y que continuamente se le está comunicando, dando ser, vegetando, dando entender.

Con esta consideración en especial San Ignacio exhorta a quien realiza los Ejercicios Espirituales a que descubra, en la creación entera, la presencia de Dios que labora en ella, saliendo de sí, para encontrarse con su criatura, con el ser humano creado a su imagen y semejanza. Y esta es una labor -valga decirlo- continua: no es una acción finalizada. Dios sigue trabajando constantemente en su obra de creación en un continuo presente que evoca una acción permanente y nunca acabada, aun cuando él vea que su obra está bien. A este respecto, Jesús M. Granero afirma:

[En] realidad, no deberíamos decir, hablando propiamente, que Dios creó el mundo, sino que continuamente lo crea. En la esencia de cada cosa, el acto creador de Dios es lo más íntimo que hay en ella, de forma que el ser y todo ser está recibiendo continuamente de Dios toda su realidad. ${ }^{35}$

Llegados a este punto es menester recordar la lógica en la que Ignacio desea que se realice este último ejercicio, a saber, la lógica del amor, en el que el amante y el amado se comunican mutuamente todo lo que tienen y pueden; lógica que ya habíamos comentado en nuestro primer apartado. Es necesario recordarlo pues no se trata solo de contemplar y considerar pasivamente el trabajo de Dios por nosotros en toda la creación; antes bien, en esta última oración, Ignacio quiere que el ejercitante sea capaz de mirar hacia atrás y ver con gratitud todos los dones "de creación, redención y dones particulares" ${ }^{\prime 6}$ recibidos durante la experiencia, y que pueda encontrar en ellos un amor tan infinito y tan diáfano, de parte de Dios para con él, que no pueda dar otra respuesta distinta a la del compromiso total y la entrega de su persona al trabajo de Dios por el mundo, de tal suerte que, desde el afecto, desde la afección visceral, el ejercitante pueda ofrecerse diciendo:

Tomad, Señor, y recibid toda mi libertad, mi memoria, mi entendimiento y toda mi voluntad, todo mi haber y mi poseer; vos me lo disteis, a vos, Señor, lo torno; todo es vuestro, disponed a toda vuestra voluntad; dadme vuestro amor y gracia, que esta me basta. ${ }^{37}$

Vemos entonces cómo en los dos textos que estamos estudiando se evidencia, en el contexto de la creación, el papel fundamental de la categoría trabajo como obra de Dios y como tarea del ser humano; podríamos decir, trabajo por la vida, por el mantenimiento y por el cuidado de la vida en la obra creada.

\footnotetext{
${ }^{35}$ Granero, "Nuestra fe católica. La creación", 204.

${ }^{36}$ San Ignacio de Loyola, Ejercicios espirituales 234.

${ }^{37}$ Ibíd.
} 
Este papel preponderante del trabajo, como elemento común en ambos escritos, nos deja ver la importancia que este tiene en la perspectiva de una reflexión teológica acerca de la obra creada. No en vano el pensamiento de hombres de Iglesia, como el papa Pablo VI, nos deja ver el papel fundamental que este juega en la continuación de la actividad creadora de Dios:

[El] trabajo ha sido querido y bendecido por Dios. Creado a imagen suya, "el hombre debe cooperar con el Creador en la perfección de la creación y marcar, a su vez, la tierra con el carácter espiritual que él mismo ha recibido". Dios, que ha dotado al hombre de inteligencia, le ha dado también el modo de acabar de alguna manera su obra; ya sea el artista o artesano, patrono, obrero o campesino, todo trabajador es un creador. [...]. Más aún, viviendo en común, participando de una misma esperanza, de un sufrimiento, de una ambición y de una alegría, el trabajo une las voluntades, aproxima los espíritus y funde los corazones; al realizarlo, los hombres descubren que son hermanos. ${ }^{38}$

Así las cosas, el trabajo viene a ser la participación activa del ser humano en la actividad creadora de Dios y, al mismo tiempo, la responsabilidad que Dios le otorga para que continúe con esa acción divina; y esta responsabilidad -como veremos adelante- no debemos entenderla en los términos de explotación y dominación de toda la realidad creada, sino asumirla en el horizonte de armonía con la creación que nos proponen los relatos del Génesis y en la lógica del mantenimiento de la vida en la cual nos sumerge Ignacio en su contemplación para alcanzar amor.

Tal forma de entender y considerar la categoría trabajo que hemos venido presentando a la luz de los dos escritos abordados, nos regresa de forma implícita a la primera categoría tratada, a saber, la de comunión, en cuanto nuestro trabajo, por iniciativa divina, está llamado a entrar en comunión con el trabajo de Dios, de manera que sea una sola realidad que tienda siempre al mantenimiento de la vida y, por eso mismo, a su salvación.

Esta última idea la recoge bellamente Benjamín González Buelta cuando, al referirse al pasaje en el que Jesús cura a un enfermo en la piscina de Betesda en Sábado (Jn 5,1-18), dice:

El hecho de que Dios sea un trabajador sin sábado, le da una dimensión sorprendente a nuestro propio trabajo que se añade al suyo y nos une con él de tal manera, que no sabemos dónde acaba nuestra mano, dónde empieza la suya y cómo se unen las dos. ${ }^{39}$

\footnotetext{
${ }^{38}$ Pablo VI, "Carta encíclica Populorum progressio sobre la necesidad de promover el desarrollo de los pueblos (1967)" 27.

${ }^{39}$ González Buelta, "Dios trabaja”, 213.
} 
De esta forma, encontramos muy presente, tanto en los relatos de creación (sobre todo, en el segundo) como en el texto ignaciano de "Contemplación para alcanzar amor", la categoría trabajo bien puede dar pie para una reflexión más amplia en términos teológicos de esta actividad tan propia del ser humano. y que desde el horizonte de la creación se nos muestra como una manera digna y sublime con la que este coopera y se vincula a la acción salvadora de Dios o, si se quiere, al trabajo del Creador por hacer cada vez más divina su obra creada.

La categoría que hemos tratado de esbozar pone en el escenario otro elemento fundamental que sugiere el análisis de los relatos de creación y del texto ignaciano, a saber, el papel esencial que el ser humano tiene en la creación; un papel que -como veremos- no se cifra en el dominio absoluto de la naturaleza creada, sino en la administración armónica y amorosa de dicha creación, por cuanto esta es imagen y semejanza del Dios creador. Acerquémonos pues a esta última categoría en nuestro apartado final.

\section{El ser humano: protagonista en el cuidado y protección de la creación}

Antes de adentrarnos en el análisis de la categoría final que deseamos proponer a partir de nuestro acercamiento a los relatos de creación, del Génesis, y al texto ignaciano "Contemplación para alcanzar amor", debemos hacer una consideración inicial sobre el antropocentrismo que ha imperado en el pensamiento teológico de Occidente y que ha puesto en segundo plano los discursos sobre el cuidado de la creación, o incluso ha llegado a invisibilizarlos.

En efecto, si hacemos una mirada rápida por algunos exponentes clásicos de la teología occidental, nos damos cuenta de que el ser humano está en la cúspide de la creación, es la criatura por antonomasia, la que ostenta el poder otorgado por Dios de "someter y dominar" la creación. Así, un pensador como San Agustín de Hipona, ciertamente influenciado por el platonismo y el neoplatonismo, concibe en los seres de la creación una suerte de jerarquía u organización jerárquica en la que el ser humano estaría en la cúspide respecto de los demás seres creados.

En efecto, el obispo de Hipona, en su comentario sobre el libro del Génesis, afirma que todos los seres fueron creados de acuerdo con un orden divino: "...fue creado todo simultáneamente según un orden preestablecido" ${ }^{40}$. En este orden "está antes el Verbo, por quien es hecha la creación”"11 de tal manera que en su mente ya

\footnotetext{
${ }^{40}$ San Agustín de Hipona, Interpretación literal del Génesis IV, 33.

${ }^{41}$ Ibíd. IV, 32.
} 
están las ideas de todos los seres posibles -argumento de marcados tintes platónicosy, entonces, al tomar como modelos esas ideas, va creándolos de acuerdo con el orden que él mismo ha concebido en su mente.

Vemos entonces cómo, para San Agustín, en los seres de la creación hay un orden ya establecido por el Creador y, de acuerdo con ese orden, cada ser posee un grado de perfección que le ha sido otorgado por él, siendo el ser humano, en virtud de su creación a imagen y semejanza de Dios y en cuanto compuesto de cuerpo y de alma, el ser con un mayor grado de perfección, después de los ángeles.

En la misma línea, Santo Tomás de Aquino, uno de los mayores teólogos de Occidente, estableció un orden jerárquico de los seres de tal forma que Dios, que es el ser por excelencia -si se nos permite usar esta expresión-, y la causa de todos los seres, es quien establece este orden o, en sus palabras, es el origen de la desigualdad de las $\operatorname{cosas}^{42}$. Dicho orden, de acuerdo con el Aquinate, sería entendido de la siguiente manera:

[En] las cosas naturales, parece que las especies están ordenadas escalonadamente. Así, los compuestos son más perfectos que sus elementos, y las plantas más que los minerales, y los animales más que las plantas, y los hombres más que los otros animales. Así, en cada uno de ellos se encuentra una especie más perfecta que la de los otros. ${ }^{43}$

De acuerdo con la cita anterior, queda claro que, para Tomás de Aquino, el ser humano, respecto de los demás seres materiales, es el más perfecto, y lo es en virtud de que posee alma como parte esencial de su naturaleza: "La tesis fundamental del Aquinate acerca de la naturaleza humana, entonces, es que nosotros no solo somos cuerpos, sino cuerpos animados por una cierta especie de forma, un alma." ${ }^{44} \mathrm{El}$ alma tiene una perfección mayor por cuanto es inmaterial y tiene un carácter formal; entonces está mucho más cercana a la naturaleza del ser de Dios, que es la perfección suma. Por ello, el ser humano, en virtud de su alma, es más perfecto que los demás seres materiales creados en cuanto estos carecen de alma.

Tanto San Agustín como Santo Tomás, hombres de Iglesia que han dado base al pensamiento teológico occidental, nos presentan una concepción de la creación en la que el ser humano es su centro, percepción que ha regido la reflexión de la teología en muchas de las esferas de la Iglesia, incluyendo el pensamiento del magisterio.

\footnotetext{
${ }^{42}$ Santo Tomás de Aquino, Suma teológica, q. 47, art. 2.

${ }^{43}$ Ibíd.

${ }^{44}$ Pasnau, "Philosophy of Mind and Human Nature", 351. "Aquinas's fundamental thesis about human nature, then, is that we are not just bodies, but bodies animated by a certain kind of form, a soul". La traducción es mía.
} 
Podríamos decir que solo a partir del pontificado de Francisco hubo un pronunciamiento explícito y una preocupación evidente por la relación de los seres humanos con la naturaleza, pues los papas anteriores, aunque han considerado este tipo de temas, lo han hecho de manera tangencial y casi siempre desde una visión antropocéntrica. Con la encíclica Ludato si ${ }^{2} 5$, el papa Francisco inaugura, por así decirlo, una nueva era en el pensamiento magisterial y teológico de la Iglesia, pues pone en el centro de la vida eclesial la preocupación por la comunión entre el ser humano y el resto de la obra creada; y decimos comunión siguiendo la afirmación del padre Gustavo Baena respecto de dicha encíclica:

El fundamento teológico del razonamiento ecológico del Papa es la unidad de toda la creación: 'Las criaturas de este mundo no pueden ser consideradas un bien sin dueño. Son tuyas, Señor, que amas la vida' (Sb 11.26). Esto provoca la convicción de que, siendo creados por el mismo Padre, todos los seres del universo estamos unidos por lazos invisibles y conformamos una especie de familia universal, una sublime comunión que nos mueve a un respeto sagrado, cariñoso y humilde. ${ }^{46}$

Por estas razones, en los tiempos modernos, numerosos intelectuales han llegado a realizar juicios tajantes culpando a la Iglesia y a su pensamiento teológico de ser los causantes de la debacle ecológica a la que nos enfrentamos:

Dios planeó todo [...] explícitamente para el beneficio y dominio del hombre: nada en la creación física tenía otra finalidad que la de servir los fines del hombre. Y aunque el cuerpo de este está hecho de barro no es simplemente una parte de la naturaleza: está hecho a imagen y semejanza de Dios. [...] El cristianismo, especialmente en su forma occidental, es la religión más antropocéntrica de la historia. ${ }^{47}$

La percepción tan fuerte que se evidencia en la cita anterior podría parecernos injusta a quienes hemos sido partícipes de la vida de fe y de la espiritualidad de la Iglesia; con todo, sí es cierto que ante el marcado antropocentrismo que ha dominado el pensamiento teológico hasta hace muy poco, y ante la tergiversación en la interpre-

\footnotetext{
${ }^{45}$ Respecto de esta encíclica del papa Francisco, ha habido bastantes comentarios y reflexiones que pueden enriquecer y ampliar la perspectiva desarrollada en esta última categoría; aquí presento solo algunos de ellos: Piro, "La ecología en el magisterio de la Iglesia"; Albareda, "Aportaciones de la Laudato si' en el contexto de la agenda 2030 para el desarrollo sostenible"; Camacho Laraña, "Laudato si: el clamor de la tierra y el clamor de los pobres. Una encíclica más que ecológica"; Pineda Rivera, "De un antropocentrismo despótico a una ecología integral: algunos comentarios en torno a la encíclica Laudato si, del papa Francisco"; De Roux, "El Papa de la tierra"; Velasco, "Laudato si. Ecología es hacer justicia. Hacer justicia es ajustar a los seres humanos y al mundo".

${ }^{46}$ Baena, "Sentido de la encíclica Laudato si”, 17.

${ }^{47}$ White Jr., Machina ex Deo: la tecnología y la cultura, 98.
} 
tación de textos como los relatos de creación del Génesis, es de esperar que aparezcan este tipo de juicios seńalando y culpando a la Iglesia y a la teología de generar tales comportamientos adversos frente a la obra creada. Al respecto, Gunton dice:

La forma que el mundo adquiere está determinada en gran medida por lo que nosotros, la creación humana, hacemos de él. Una vez más podemos decir que muchos desastres de todas las épocas, pero especialmente de la modernidad, derivan de una comprensión equivocada de dicha relación. La imagen ha sido entendida de manera individualista, más que en términos de ser en relación, de modo que han surgido pautas de alienación en la relación con otros seres humanos, de dominación más que de dominio del resto de la creación. ${ }^{48}$

Dichas pautas de alienación a las que se refiere Gunton son precisamente las que podemos resignificar y las que queremos cambiar con estos nuevos acercamientos a los textos bíblicos y a la espiritualidad cristiana, fuentes en las que podemos encontrar elementos de mucha riqueza, tanto para nuestra vida de fe como para la construcción de nuevas maneras de relacionarnos con nosotros mismos y con los demás seres de la creación. A tales nuevas formas de relación deseamos apuntar con el desarrollo de esta última categoría en la que el ser humano sigue siendo el centro de la creación, pero desde una perspectiva diferente que esbozaremos a continuación.

En el análisis que hemos venido realizando acerca de los dos relatos de creación del Génesis y del texto ignaciano "Contemplación para alcanzar amor" hemos reconocido que el ser humano es el protagonista: en el primer relato de creación es la criatura con la que el verbo bará, atribuido únicamente a Dios, llega a su plenitud, y es el único ser vivo creado a la imagen y semejanza del Creador; en el segundo relato, el hombre es la primera de las criaturas en ser llamado a la vida y, además, recibe un aliento de vida de parte de Dios, lo cual lo pone en una relación privilegiada con el Creador: “...el Señor Dios infunde en el hombre el aliento de vida [...]. El Señor Dios no realiza esta acción con los animales (Gn 2,19), sino solo con el hombre, lo que indica la relación especial y personal de Dios con el ser humano" ${ }^{49}$. Finalmente, en la "Contemplación para alcanzar amor", el ejercitante es el centro del ejercicio y la totalidad de los puntos que lo componen invitan a que este (el ser humano, el ejercitante) contemple cómo Dios trabaja por él en la creación. Ahora, en cada uno de esos textos, hay unos detalles que nos permiten abrirnos a una nueva manera de entender ese protagonismo humano en la obra creada y que queremos comentar en seguida.

\footnotetext{
${ }^{48}$ Gunton, Unidad, Trinidad y pluralidad. Dios, la creación y la cultura de la modernidad, 246.

${ }^{49}$ Darder, El verdadero Israel testigo del Dios liberador. Itinerario de vida cristiana a la luz del Pentateuco y los libros históricos, 67.
} 
- En primer lugar, vamos a remitirnos al relato de creación que encontramos en Gn 1,1-2,3, específicamente al v. 26 del Capítulo 1, en el cual el narrador nos presenta la creación del ser humano a "imagen y semejanza” del Creador. Como hemos visto, esta condición de imagen y semejanza ha servido como argumento para que durante siglos de producción teológica se haya considerado al ser humano como una especie en grado superior a las demás especies. Es probable que en la mentalidad semita que se encuentra plasmada en este relato esa sea la concepción respecto del ser humano; sin embargo, es menester que llamemos la atención sobre algunos matices de estos dos términos que nos ayudarán a ampliar nuestro horizonte a este respecto.

La creación del ser humano -como hemos dicho- fue hecha a imagen y semejanza del Creador. Los términos hebreos para designar estos dos vocablos son çélem (imagen), que significa más ampliamente la reproducción real, la copia; y dĕmut (semejanza) que es un verbo sustantivo abstracto y significa de modo principal algo abstracto también: "apariencia", "similitud", "correspondencia". El uso de estos vocablos evoca entonces el pensamiento sacerdotal que presenta al ser humano como realmente parecido a Dios, lo cual denota cercanía e inmediatez entre Dios y su criatura humana. ${ }^{50}$

Este pensamiento, dicho sea de paso, no es ajeno a las culturas circundantes del Antiguo Oriente, en las cuales, cuando el rey no podía hacerse presente en lugares muy alejados de su palacio, mandaba a construir una estatua con su figura, que fuera casi exacta a su apariencia física, de modo que al verla los súbditos sintieran que allí estaba la presencia de su rey. Esto último nos deja ver la plasticidad con la que aquí se toma la palabra imagen.

Tal plasticidad nos sitúa en el sentido profundo de los vocablos imagen y semejanza que el mismo relato del Génesis nos sugiere, pues ellos no podrían entenderse totalmente sin el mandato que Dios da al ser humano una vez lo ha creado, a saber, el de dominar sobre los peces, las aves y los animales terrestres y el de someter la tierra. Estas funciones de señorío que son propias de Dios, el único dador de vida, él mismo las concede al ser humano como forma de hacer presente su majestad y divinidad en la tierra; es decir, el ser humano viene a constituirse en el signo de la

\footnotetext{
${ }^{50}$ Es interesante ver en este caso la originalidad de la propuesta semita de la creación, pues otros relatos, como el Enuma Elish, por ejemplo, cuando se refieren a la creación del hombre lo hacen en términos de servicio a los dioses, es decir, el ser humano es creado para que sirva a los dioses y estos puedan descansar: "En verdad, un ser humano crearé para que [...] cargando con el servicio de los dioses, estos puedan reposar" (Lara Peinado (trad. y ed.), Enuma Elish. Poema babilónico de la creación VI, 7-8). Hay aquí, por tanto, una concepción utilitarista y, por qué no, de esclavitud del ser humano respecto de las deidades, elementos a los que se opone radicalmente el relato del Génesis.
} 
majestad divina en virtud de su semejanza a Dios, lo cual nos remite a esa costumbre real de construir estatuas del rey en los lugares alejados del reino.

- $\quad$ En segundo lugar y en línea con lo dicho previamente, los términos imagen y semejanza, en este relato, adquieren su máximo sentido con el mandato que -en el mismo versículo-Dios da al ser humano después de que lo ha creado, al darle potestad para dominar sobre los animales y para someter la tierra. Estos dos verbos, "dominar" y "someter", que han sido tan mal interpretados por muchos creyentes y no creyentes y que se han usado como el argumento sagrado para justificar la superioridad del ser humano y su relación destructora con el resto de la creación, quieren comunicarnos otra realidad en la lógica del relato, que conviene señalar acudiendo a las palabras usadas en el texto hebreo ${ }^{51}$.

En efecto, en el idioma hebreo las palabras empleadas para estos dos verbos son radá (pisar, patear, ejercer dominación) y kabăśs (pisotear, subyugar). De estas dos, la que tiene un matiz más fuerte es la segunda, pues alude incluso al sometimiento de alguien mediante esclavitud. Con todo, esta acepción tan fuerte probablemente no es la que tome el verbo en este relato. Así las cosas, parece muy adecuado entender aquí los verbos radá y kabás como pisar y pisotear en un sentido más agrícola del uso de la tierra. De hecho, el mandato de someter recae directamente sobre la tierra, la cual debe ser adaptada por el ser humano, mediante la agricultura, para su supervivencia.

Tales acciones también evocan el señorío de Dios sobre la obra creada, señorío del que, gracias a la semejanza, Dios mismo hace partícipe al ser humano; pero no es un señorío absoluto sino en total referencia al Creador, de tal suerte que ese ejercicio de dominación sea un verdadero servicio a Dios que permita "llevar adelante su creación hasta que llegue su reino"s2.

Así pues, desde la perspectiva del primer relato, el ser humano sí es la esencia de la creación, pero no porque sea superior y pueda ejercer un dominio a su antojo frente a ella, sino porque, en cuanto imagen y semejanza del Creador, está llamado

\footnotetext{
${ }^{51}$ A propósito del significado de estos dos términos hebreos en el relato de Gn 1,1-2,3, se podría decir que se entienden como la labor de administrar. En efecto, el hombre, en tanto imagen y semejanza de Dios, no es más que un administrador, esto es, un cuidador, un protector de la creación. Esta acepción la deja bien clara Ian Hart cuando nos dice que "el mandato de 'dominar' [...] no es simplemente una declaración de que el hombre gozará de un rango real; es el reparto de una tarea, una tarea en curso que se traduciría bien con la palabra más moderna 'administrar" (“The command to 'have dominion' [...] is not merely a declaration that man will enjoy kingly rank; it is the apportioning of a task, an ongoing task which would be well translated by the more modern word 'manage" (Hart, "Genesis 1:1-2:3 as a Prologue to the Book of Genesis", 323). La traducción es mía.
}

${ }^{52}$ González Faus, "La creación en el Popol Vuh”, 248. 
a ser su representante en medio de la obra creada y, por tanto, llamado a cuidar de la vida, a garantizar que los seres creados sigan emanando vida y sigan siendo, por tanto, el reflejo fehaciente de la habitación del dueño de la vida en ellos: "El hombre debe velar para que la creación se desarrolle según el proyecto de Dios" ${ }^{33}$.

- En tercer lugar, el ser humano, desde lo que nos presenta el segundo relato, fue la primera criatura en ser llamada a la vida, de tal suerte que vino a habitar una tierra que estaba deshabitada. El relato lo pone en los siguientes términos: "Entonces Yahveh Dios formó al hombre [adam] con polvo del suelo [adamah], e insufló en sus narices aliento de vida, y resultó el hombre un ser viviente" (Gn 2,7).

Vale la pena llamar la atención sobre la asonancia entre los términos adam y adamah, pues ella denota "la solidaridad original entre el hombre y el suelo" ${ }^{44}$, con lo cual, desde el horizonte de este relato, el ser humano y la tierra se pertenecen, poseen la misma materialidad, fueron creados con el mismo material, tienen la misma composición y ello, entonces, nos pone ya en la perspectiva de una unión íntima, de una comunión entre el ser humano y la tierra, en virtud de su origen creacional común.

Precisamente, de cara a este origen compartido entre el ser humano y la tierra, Alejandro Botta se expresa de forma sublime diciendo: “...el hombre y la tierra se pertenecen. La tierra sin el hombre queda estéril, así como un hombre sin tierra vive el exilio"55; por esta razón, el ser humano, al ser el centro de la obra creada, solo puede vivir en comunión con ella, cuidándola y protegiéndola porque, al hacerlo, se está cuidando y protegiendo él mismo en cuanto comparten el mismo origen y fueron creados con la misma materialidad.

- En cuarto y último lugar nos ubicamos en el texto ignaciano de "Contemplación para alcanzar amor”, en el que nos topamos con una propuesta que también tiene un marcado acento antropocéntrico. No obstante, dicha propuesta, lejos de mostrarnos un arrogante protagonismo del ser humano, nos sitúa en una dinámica de ofrecimiento al Dios creador.

En efecto, en la dinámica de esta contemplación, una vez que el ejercitante ha reconocido el amor de Dios -quien se le da en la creación y quien trabaja por él habitando en las criaturas y en él mismo, haciéndole su templo-, no le queda otra respuesta que la entrega total de su ser a ese Dios creador, ofreciendo lo que es como ser humano, y lo que tiene y puede, todo enmarcado en la óptica del amor en

${ }^{53}$ Darder, El verdadero Israel testigo del Dios liberador. Itinerario de vida cristiana a la luz del Pentateuco y los libros históricos, 53.

${ }^{54}$ García López, El Pentateuco. Introducción a la lectura de los cinco primeros libros de la Biblia, 81.

${ }^{55}$ Botta, El Pentateuco. La Biblia Hebrea en perspectiva latinoamericana. Introducción al Antiguo Testamento, 63 . 
cuanto comunicación. Así, ante tanto amor y bien recibido de Dios, el ejercitante se ve volcado a pagar con un amor semejante y a cumplir, en todo, la voluntad divina.

[...si] el ejercitante "hace en todo la voluntad de Dios" conocida en la segunda semana, responde con amor de obras al amor de obras de Dios; si logra la perfección que describen los tres postreros puntos, su amor de obras quedará revestido de caracteres y delicadezas muy semejantes a las que posee el amor de obras de Dios. ${ }^{56}$

Tal respuesta de amor que hace el ejercitante es -por decirlo de alguna formala manera como Ignacio presenta la responsabilidad que tenemos de vincularnos a la acción amorosa de Dios en su creación; por eso, en la perspectiva del amor, se constituye en una respuesta de amor que el ejercitante da frente a ese amor de Dios que toma la iniciativa y que se da en las criaturas.

Con esta dinámica del amor, Ignacio nos muestra un camino precioso en el que podemos asumir esa tarea de ser administradores y gobernadores de la creación de Dios, no como una obligación, ni tergiversándola -como se ha hecho-, explotando de forma indiscriminada los demás seres creados, sino amándolos como escenario en el cual Dios se nos entrega, se nos hace presente y trabaja por nosotros.

\section{Conclusión}

La crisis medioambiental que enfrentamos en el mundo contemporáneo nos lleva a preguntarnos a quienes nos consideramos personas de Iglesia cuál es nuestra responsabilidad y nuestro compromiso como bautizados frente a tal problemática ecológica. ¿Qué estamos llamados a hacer como cristianos para remediar en parte esta explotación desmedida de los recursos naturales que Dios mismo creó?

Estos interrogantes nos llevaron a buscar, ubicados en un horizonte de reflexión teológica, en las Sagradas Escrituras, específicamente en los relatos de creación del Génesis, y en textos de espiritualidad cristiana como los Ejercicios espirituales de San Ignacio, en su "Contemplación para alcanzar amor", elementos que nos pudieran iluminar posibles respuestas que permitan orientar nuestro compromiso con el cuidado y el respeto por nuestra casa común ${ }^{57}$.

En tal búsqueda encontramos tres categorías que, vistas en conjunto, nos dan pistas para proponer nuevos escenarios teológicos que enriquezcan nuestra vida de fe y que nos movilicen a comprometernos por el cuidado y el respeto de la creación:

\footnotetext{
${ }^{56}$ Iglesias, "La contemplación para alcanzar amor", 309.

${ }^{57}$ Francisco, “Carta encíclica Laudato si” sobre el cuidado de la casa común (2015)” 210.
} 
- La de comunión entre el ser humano y los demás seres creados, porque todos comparten la misma mesa o la misma bendición. La comunión viene de la tierra revestida con el poder de dar vida. Ella es madre digna de nuestro respeto y de todo nuestro cuidado, pues ella alberga en su seno la capacidad de comunicar la vida concedida por Dios creador.

- La del trabajo, que también nos pone en una perspectiva de comunión y de dinamismo de amor, ya que -de acuerdo con Ignacio- al contemplar admirablemente todos los dones que Dios nos ha dado, y más aún, al contemplar cómo Dios se nos comunica, se nos da en cada ser de la creación, no podemos más que entregarnos a él con todo lo que somos y tenemos, de suerte que, al reconocer el trabajo de Dios por nosotros en su creación, nos sintamos movidos a vincularnos a dicho trabajo, entregándole cuanto somos, siempre en el horizonte del "dar y comunicar el amante al amado lo que tiene o de lo que tiene o puede, y así, por el contrario el amado al amante" 58 .

- La tercera categoría es la de la centralidad del ser humano en la creación: pero no es una centralidad cifrada en la superioridad y el poder (superioridad que conlleva a la explotación arbitraria e indiscriminada del resto de la obra creada en cuanto el hombre y la mujer ostentan la condición de ser creados a imagen y semejanza del Creador); antes bien, es una centralidad que se materializa en el cuidado y la protección de la vida toda, pues ella es la máxima expresión de la presencia de Dios en la historia.

Son el hombre y la mujer quienes tienen esa responsabilidad, precisamente en virtud de que son, nuevamente, imagen y semejanza del dueño de la vida, representantes suyos en la tierra, y quienes han recibido de él la capacidad para someter la tierra y para administrar los demás bienes de la creación. Precisamente en línea con esta última consideración y a manera de reflexión final, Gianfranco Ravasi nos dice:

Afirmada con vigor la dignidad "regia" del hombre y de la mujer en el concierto de lo creado, no es menos indispensable subrayar que el señorío humano no es autonomía absoluta y brutal. De Dios recibe la humanidad su primado. Y ha sido este mismo Dios quien ha creado y juzgado todas las restantes realidades como "buenas". El hombre no tiene la facultad de abusar y de destruir a su capricho. Esta página que celebra la "bondad" de toda la creación confiada al hombre y a la mujer se convierte, por tanto, en acta de acusación contra la sociedad cuando altera con violencia y egoísmo el equilibrio de lo creado, sobre el que solo goza de usufructo. Se convierte en acta de acusación contra la tiranía vanidosa, ciega y a menudo cruel de la humanidad, que rompe, devasta, ensucia y humilla, con su egoísmo irracional e inicuo, "las obras de las manos de

\footnotetext{
${ }^{58}$ San Ignacio de Loyola, Ejercicios espirituales 231.
} 
Dios". El hombre debería ser, muy al contrario, el liturgo de la creación, el que hace visible y audible la alabanza implícita y secreta que asciende al Creador del Sol y de la Luna, de las "fúlgidas estrellas", de la nieve y la niebla, del "viento de la ventisca", de las colinas, de los árboles frutales, de los cedros, de las fieras y ganados, de los reptiles y las aves, como canta el Salmo $148 .{ }^{59}$

Así pues, el hombre y la mujer están llamados, desde su misma condición de criaturas, a ser "liturgos" de la creación, a propender por el cuidado y la protección de la obra creada, a hacer de su existencia y de su paso por la tierra un camino en el que transparenten la presencia del Dios creador a través de su amor, respeto y comunión con el resto de la creación.

\section{Referencias}

Albareda Tiana, Silvia. "Aportaciones de la Laudato si' en el contexto de la agenda 2030 para el desarrollo sostenible". Scripta theologica 48 (2016): 443-462.

Alonso Schökel, Luis. La biblia de nuestro pueblo. Madrid: Mensajero, 2008.

Baena, Gustavo. "Sentido de la encíclica Laudato si". En Abriendo Horizontes 8, dirigido por Margarita Cadavid, 13-20. Medellín: Centro de Fe y Culturas, 2015.

Botta, Alejandro. El Pentateuco. La Biblia hebrea en perspectiva latinoamericana. Introducción al Antiguo Testamento. Estella (Navarra): Verbo Divino, 2014.

Botterweck, Johannes; Helmer Ringgren; y Heinz-Josef Fabry. Theological Dictionary of the Old Testament. Vol. II. Grand Rapids (MI): Eerdmans Publishing Co., 1974.

Camacho Laraña, Idelfonso. "Laudato si': el clamor de la tierra y el clamor de los pobres. Una encíclica más que ecológica”. Revista de fomento social71 (2016): 59-79.

Carreira, Manuel. "El Génesis en términos de la ciencia moderna". E-Aquinas 5 (2007): 1-19.

Concilio Vaticano II. "Decreto Ad gentes sobre la actividad misionera de la Iglesia (1965)". Vatican, http://www.vatican.va/archive/hist councils/ii vatican council/documents/vat-ii decree 19651207 ad-gentes sp.html (consultado el 13 de abril de 2019).

Crescimbeni, Giuseppe. San Francisco de Asis. Bogotá: San Pablo, 2017.

${ }^{59}$ Ravasi, Guía espiritual del Antiguo Testamento. El libro del Génesis (1-11), 55. 
Darder, Francesc. El verdadero Israel testigo del Dios liberador. Itinerario de vida cristiana a la luz del Pentateuco y los libros históricos. Estella (Navarra): Verbo Divino, 2004.

De Roux, Francisco. "El Papa de la tierra”. Revista Javeriana. Laudato si. El cuidado de la casa común 818 (2015): 23-26.

Francisco. "Carta encíclica Laudato si" sobre el cuidado de la casa común (2015)". Vatican, http://w2.vatican.va/content/dam/francesco/pdf/encyclicals/documents/papa-francesco_20150524_enciclica-laudato-si_sp.pdf (consultado el 13 de abril de 2019).

García de Castro, José (dir.). Diccionario de espiritualidad ignaciana. Bilbao: Mensajero-Sal Terrae, 2007.

García López, Félix. El Pentateuco. Introducción a la lectura de los cinco primeros libros de la Biblia. Estella (Navarra): Verbo Divino, 2003.

González Buelta, Benjamín. "Dios trabaja”. Manresa. Revista de Espiritualidad Ignaciana 79 (2007): 213-225.

González Faus, José Ignacio. "La creación en el Popol Vub”. Revista Latinoamericana de Teología 33 (1994): 245-265.

Granero, Jesús. "Nuestra fe católica. La creación". Manresa. Revista de Espiritualidad Ignaciana 45 (1973): 203-205.

Gunton, Colin. Unidad, Trinidad y pluralidad. Dios, la creación y la cultura de la modernidad. Salamanca: Sígueme, 2005.

Hart, Ian. "Genesis 1:1-2:3 as a Prologue to the Book of Genesis". Tyndale Bulletin 46 (1995): 315-336.

Ibánez, Andrés. Para comprender el libro del Génesis. Estella (Navarra): Verbo Divino, 1999.

Iglesias, Eduardo. "La contemplación para alcanzar amor”. Manresa. Revista de Espiritualidad Ignaciana 8 (1932): 301-316.

Lara Peinado, Francisco (trad. y ed.). Enuma Elish. Poema babilónico de la creación. Madrid: Trotta, 1994.

Levoratti, Armando. Comentario bíblico latinoamericano. Estella (Navarra): Verbo Divino, 2005.

Loza Vera, José. Comentarios a la Nueva Biblia de Jerusalén. Génesis 1-11. Bilbao: Desclée de Brouwer, 2005. 
Loza Vera, José, y Raúl Duarte Castillo. Introducción al Pentateuco. Génesis. Estella (Navarra): Verbo Divino, 2007.

Navarrete, Luis. "Aproximación bíblico-teológica a la Contemplación para alcanzar amor". Apuntes ignacianos 66 (2012): 17-39.

Pablo VI. "Carta encíclica Populorum progressio sobre la necesidad de promover el desarrollo de los pueblos (1967)". Vatican, http://w2.vatican.va/content/paul-vi/ es/encyclicals/documents/hf p-vi enc 26031967 populorum.pdf (consultado el 17 de abril de 2019).

Parente, Pietro; Antonio Piolanti; y Salvatore Garofalo. Diccionario de teología dogmática. Barcelona: Editorial Litúrgica Española, 1955.

Pasnau, Robert. "Philosophy of Mind and Human Nature". En The Oxford Handbook of Aquinas, editado por Brian Davies y Eleonore Stump. New York (NY): Oxford University Press, 2012. DOI: 10.1093/oxfordhb/9780195326093.013.0027

Pikaza, Xabier, y Nereo Silanes. Diccionario teológico. El Dios cristiano. Salamanca: Secretariado Trinitario, 1992.

Pineda Rivera, Diego Antonio. "De un antropocentrismo despótico a una ecología integral: algunos comentarios en torno a la encíclica Laudato si', del papa Francisco". Revista Javeriana. Laudato si. El cuidado de la casa común 818 (2015): 65-78.

Piro, Ezequiel. "La ecología en el magisterio de la Iglesia”. Dios y el hombre 3 (2019): $1-12$.

Rambla, José. "La creación en los Ejercicios: comunión y servicio". Manresa. Revista de Espiritualidad Ignaciana 70 (1997): 227-243.

Ravasi, Gianfranco. Guia espiritual del Antiguo Testamento. El libro del Génesis (1-11). Barcelona: Herder, 1992.

Rodríguez Osorio, Hermann. "Contemplación para alcanzar amor”. Apuntes ignacianos 66 (2012): 4-16.

San Agustín de Hipona. Interpretación literal del Génesis. Introducción, traducción y notas de Claudio Calabrese. Navarra: Eunsa, 2006.

San Ignacio de Loyola. Ejercicios espirituales. Bilbao: Mensajero, 1991.

San Juan de la Cruz. "Cántico espiritual". En Poesía completa, edición e introducción de Cristóbal Cuevas García, 150-153. Barcelona: RBA Editores, 1995. 
Santo Tomás de Aquino. Suma teológica. Madrid: Espasa-Calpe, 1966.

Valverde, Carlos. "Contemplación para alcanzar amor y Medio divino". Manresa. Revista de Espiritualidad Ignaciana 42 (1970): 157-168.

Velasco, Pedro. "Laudato si. Ecología es hacer justicia. Hacer justicia es ajustar a los seres humanos y al mundo”. Ibero 42 (2016): 18-23.

Von Rad, Gerhard. El libro del Génesis. Salamanca: Sígueme, 2008.

Waldman, Mauricio. "Eco-kasher y oiko-menismo". Revista de interpretación biblica latinoamericana, Ribla 23 (1996): 13-14.

Westermann, Claus. Genesis. London: T\&T Clark International, 2004.

White Jr., Lynn. Machina ex Deo: la tecnología y la cultura. México, D.F.: Editores Asociados, 1973. 